\title{
História de vida e projeto : a história de vida como projeto e as "histórias de vida" a serviço de projetos*
}

Marie-Christine Josso

Université de Genève

\section{Resumo}

Vinte anos de práticas de reflexão, sobre e nos procedimentos de "histórias de vida em formação", permitem fazer uma síntese sobre sua contribuição e compreender a formação do ponto de vista dos sujeitos aprendizes, bem como as aspirações de conhecimento em relação aos contextos de utilização de perspectivas biográficas.

0 artigo oferece, desse modo, um amplo panorama europeu e internacional de autores que publicaram suas pesquisas nesse âmbito e distingue as histórias de vida como projeto de conhecimento das perspectivas biográficas temáticas a serviço de projetos específicos.

Nessa diversidade, porém, depreende-se uma unidade: a preocupação de construir um saber a partir de um trabalho intersubjetivo dos autores dos relatos com os pesquisadores e, por conseguinte, a preocupação de dar ao trabalho sobre e com a subjetividade um estatuto hermenêutico produzindo, no mesmo movimento, um conhecimento do processo de construção de si (self) e dos conhecimentos generalizáveis pelo seu valor de uso.

\section{Palavras-chave}

História de vida - Projetos - História das idéias - Conhecimento.
Correspondência para: Université de Genève Faculté de Psychologie et des Sciences de l'Education Uni-Batelle 9, route de Drize 1227 Carouge - Genève e-mail: josso@uni2a.unige.ch

* Tradução do original francês Histoire de vie et projet-l'histoire de vie comme projet et les "histoire de vie" au service de projets por Denice B. Catani e Helena C. Chamlian. 


\section{Life history and project : life history as a project and "life histories" attending to projects*}

Marie-Christine Josso

Université de Genève

Correspondence:

Université de Genève

Faculté de Psychologie et des

Sciences de l'Education

Uni-Batelle

9 , route de Drize

1227 Carouge - Genève

e-mail: josso@uni2a.unige.ch

* Translation from the original French Histoire de vie et projet I'histoire de vie comme projet et les "histoires de vie" au service de projets by Denice B. Catani and Helena C. Chamlian.

\section{Abstract}

Twenty years of reflections in and about procedures of "life histories in formation" allow the production of a synthesis about their contributions, and the understanding of the development from the point of view of the developing subjects. They also provide an understanding of the aspirations of knowledge about the contexts of usage of biographical perspectives.

The paper therefore offers a wide scene of European and international authors who have published their research in this field, and recognises life histories as a project of knowledge of thematic biographical perspectives attending to specific projects.

In this diversity, however, a unity can be perceived: the preoccupation with creating a knowledge based on an intersubjective collaboration between the researchers and the writers of the accounts, and therefore the preoccupation with providing the work with and about subjectivity with hermeneutic standards. At the same time knowledge of the process of creation of the self and of knowledge that can be generalised through its usage value is produced.

\section{Keywords}

Life history - Projects - History of ideas - Knowledge. 
As histórias de vida tornaram-se, há uns vinte anos, um material de pesquisa muito em voga nas ciências humanas, pois não há simpósio, colóquio ou encontro científico no qual estejam ausentes. No campo da educação, além dos trabalhos de pesquisa-formação, observa-se o desenvolvimento, nos currículos e inclusive na formação de professores (as) da rede escolar, de uma sensibilidade para a história do aprendiz e de sua relação com o conhecimento, enquanto as formações contínuas abrem-se ao reconhecimento da experiência. Além disso, numerosos procedimentos biográficos foram introduzidos para acompanhar, orientar, suscitar ou facilitar a elaboração dos projetos pessoais de indivíduos em busca de uma orientação ou de uma reorientação profissional, em busca de um emprego, de mulheres que desejam trabalhar após um tempo em que acompanharam a educação de suas crianças. Como situar esse fascínio pelo singular, a individualidade, o sujeito, o vivido, o experiencial, a globalidade concreta, o existencial, a complexidade dos processos de formação etc., no movimento de idéias da segunda metade do século XX? Alguns, tais como Charles Taylor, Ken Wilber ou Robert Misrahi, dedicaram-se a essa tarefa com excelência, na sua perspectiva filosófica e epistemológica. De minha parte, gostaria de indicar alguns autores chaves entre aqueles que me acompanharam na minha abertura para esse novo paradigma e em meu engajamento intelectual na abordagem biográfica da formação do sujeito.

\section{As histórias de vida na emergência de um novo paradigma: algumas referências}

0 fascínio com relação à perspectiva biográfica parece inseparável da reabilitação progressiva do sujeito e do ator, e essa reabilitação pode ser interpretada como um retorno estabilizador após a hegemonia do modelo de causalidade determinista das concepções funcionalistas, marxistas e estruturalistas do indivíduo até o fim dos anos setenta. Entre as conseqüências da valorização desses dois conceitos para pensar as pessoas, acha-se claramente evidente uma redescoberta da problemática da intencionalidade com sua tradução pragmática nas múltiplas figuras do projeto.

Essa reabilitação do sujeito e do ator tornou-se plausivel teórica e cientificamente pelo sucesso da Teoria dos Sistemas de Bertalanfy (1972) reintroduzindo a abertura e a indeterminação no seio de uma visão determinista, quer seja linear ou multifatorial pela mediação do conceito de autopoiésis que caracteriza, no campo social, as individualidades. Em Antropologia, os trabalhos de Gregory Bateson (1980) e a Escola de Palo Alto tiveram um impacto considerável sobre a interpretação que construíramos mediante nossas interações concretas. No campo da Sociologia, Crozier e Friedberg contribuíram fortemente com "0 ator e o sistema" para dar uma tradução concreta da teoria sistêmica. No que tange à abordagem interdisciplinar, vem-me à memória que, em 1986, o Colóquio de Cerisy Pensar o sujeito hoje (GuibertSledziewski, 1988) constituiu um sinal importante do deslocamento de intelectuais de diversos horizontes para a adesão a esse novo paradigma. Enfim, no campo da Psicologia e da Educação, cabe lembrar as perspectivas de Carl Rogers, de Paulo Freire e de Bernard Honoré, como os autores de referência que prepararam o terreno de nosso interesse biográfico para abordar a formação do ponto de vista do sujeito aprendiz.

As obras de Edgar Morin (1977) publicadas sob o título geral La méthode, vieram esclarecer de modo novo a complexidade das dinâmicas bio-psico-sócio-culturais, mediante uma síntese de um conjunto de abordagens contemporâneas cobrindo a quase totalidade dos campos científicos. Capaz de autonomia inventiva e sujeito a imposições, o Anthropos 
encontra limites, uma intencionalidade em busca de lucidez, uma reflexividade atuante, recobrindo assim o direito e os deveres que o acompanham, de orientar individual e coletivamente suas atividades, suas perspectivas e sua busca de conscientização.

\section{Transição}

Os quatro volumes de Edgar Morin que desenvolvem esse novo olhar científico foram publicados na época em que nossa equipe de Genebra, Pierre Dominicé, Matthias Finger e eu mesma vislumbramos um novo horizonte teórico no campo da educação de adultos para uma abordagem da formação centrada sobre o sujeito aprendiz, utilizando a mediação de uma metodologia de pesquisa-formação articulada às histórias de vida. Algum tempo antes, Gaston Pineau começou a equacionar o campo da auto-formação, após a publicação de Produire sa vie (1983), obra que publicou em colaboração com Marie-Michèle.

As trocas na rede francófona de histórias de vida em formação, que se constituiu no começo dos anos 1980, permitiram colocar em evidência a amplitude da decifração a ser efetuada. Nós estivemos imersos em nossas abordagens fenomenológicas respectivas durante uma dezena de anos.

Em Genebra e em diversos outros locais da Suiça, ou da Europa, os pesquisadores-formadores da nossa equipe com Pierre Dominicé apresentaram a um público numeroso os procedimentos de "história de vida e formação", em nossos seminários universitários ou em nossas sessões ad hoc, e um certo número dentre elas tem, por seu turno, inovado em seus respectivos locais de trabalho, colocando as histórias de vida a serviço de seus projetos. Além disso, nós temos sido levados a introduzir as abordagens biográficas nas formações tradicionais contínuas ou para acompanhar as inovações, associando elaboração de projeto e perspectiva biográfica.
Na Europa, na América do Norte e na América do Sul têm se desenvolvido igualmente projetos de conhecimento a partir do desenvolvimento de "histórias de vida", bem como têm sido encorajados, sustentados, acompanhados ou supervisionados projetos de formação, de ação ou de intervenção utilizando as abordagens biográficas.

Assim, após uma dezena de anos, as relações entre histórias de vida e projeto podem ser apresentadas em torno de dois eixos que se nutrem mutuamente: a busca do projeto teórico de uma compreensão biográfica da formação e, a fortiori, da autoformação mediante os procedimentos de pesquisa-formação, de um lado, e, de outro, o uso de abordagens biográficas postas a serviço de projetos (projeto de expressão, projeto profissional, projeto de reinserção, projeto de formação, projeto de transformação de práticas, projeto de vida).

Fazer hoje um inventário exaustivo e crítico do conjunto das produções que caracterizam esses dois eixos do recurso às histórias de vida e os projetos aos quais eles se filiam constitui empreendimento enorme, tendo em conta a variedade dessas práticas/projetos de conhecimento, de formação e de ação. No espaço de um artigo só é possível introduzir esses dois eixos em suas grandes linhas e evocar alguns exemplos escolhidos entre as experiências e os conhecimentos mais familiares à autora.

\section{As histórias de vida como projeto de conhecimento}

Os procedimentos de histórias de vida, tal como foram desenvolvidos e dados a conhecer pelas publicações há quinze anos, parecem articular-se a dois tipos de objetivos teóricos. De uma parte, um projeto de deslocamento do posicionamento do pesquisador, mediante um refinamento de metodologias de pesquisa-formação articuladas à construção de uma história de vida. Esse refinamento 
visa a diferenciar melhor as modalidades e os papéis desempenhados no processo, as etapas e os projetos de conhecimento específicos para a pesquisa-formação. De outra parte, as contribuições do conhecimento dessas metodologias ao projeto de delimitação de um novo território de reflexão que abarca a formação, a autoformação e suas características, assim como os processos de formação específicos com públicos particulares.

A vertente do projeto metodológico é de longe a que mais tem mobilizado, individual e coletivamente tanto os pioneiros quanto a segunda geração. Provavelmente nossas opções metodológicas tinham e continuam a ter necessidade de reivindicar, de dar um lugar, justificar sua sustentação, dando uma legitimidade à mobilização da subjetividade como modo de produção de saber e à intersubjetividade como suporte do trabalho interpretativo e de construção de sentidos para os autores dos relatos. Esse cuidado metodológico exprime bem, parece-me, o desafio epistemológico (e os desafios de lugar e poder que lhe estão ligados) relativo ao valor de uso dos conhecimentos produzidos e às normas de legitimação de um saber científico. Observe-se alguns exemplos.

Em 1989, na obra Histoires de Vie (Pineau; Jobert, 1989) Gaston Pineau introduz o segundo volume com um texto cujo título não pode ser mais explícito: "Histoire de vie et crise paradigmatique en éducation". Com efeito, trata-se de explorar novas práxis, de ressaltar as questões metodológicas que lhes estão ligadas, interrogar as implicações epistemológicas do método. Nessa perspectiva, Pierre Dominicé (1990) publica, logo a seguir, sua obra L'Histoire de vie comme processus de formation, na qual ele apresenta longamente o método de pesquisa que ele denomina biografia educativa. E, em 1992, um seminário interdisciplinar organizado por Christian Léomant (1992), em Vaucresson, resulta numa publicação coletiva intitulada $L$ 'histoire de vie au risque de la recherche, de la formation et de la thérapie. Poucos anos depois, em 1994, Danielle Desmarais e Jean-Marc Pilon retornam mais uma vez ao debate, em Montreal, num simpósio da rede "História de Vida em Formação", que resulta na obra Pratiques des histoires de vie au carrefour de la formation, de la recherche et de l'intervention (Desmarais et Pilon, 1996). Em 1995, Peter Alheit e Pierre Dominicé coordenaram a publicação dos trabalhos de um colóquio da ESREA (European Society for Research in Education of Adults) em Genebra, fortemente marcados pelo debate metodológico e epistemológico entre os pesquisadores-práticos da formação e pesquisadores das ciências sociais em educação, sob o titulo The biographical approach in European adult education (Alheit, 1955). Enfim, um colóquio foi organizado em Tours, em 1996, pelo grupo regional do Grande-Oeste da rede internacional, sobre a temática do acompanhamento em nossos procedimentos biográficos, sob o título Accompagnements et histoire de vie.

Vê-se que essas obras traduzem um esforço coletivo, mas para dar a justa medida do peso da reflexão metodológica e epistemológica convém apresentar um conjunto de artigos esparsos em diversas revistas e evocar capitulos de obras de colegas da rede que abordam essas questões. Detenho-me em três exemplos recentes. Laura Formenti (1996) publicou em Adultità, uma revista da Universidade de Milão, seu trabalho "La storia que educa: contesti, metodi, procedure dell'autobiografia educativa". Jean Michel Baudoin, de Genebra, debruçou-se sobre "La dimension du groupe, seconde et primordiale: histoire de vie recherche-formation" (no prelo). E, finalmente, um artigo de Jean-Christophe Niewiadomski (1999) da rede do Grande-Oeste, intitulado "Histoire de vie en groupe et approche clinique en alcoologie".

Não poderia terminar essas referências sem indicar o trabalho de reflexão ética que foi proposto mediante uma "Carta de princípios" 
emitida pelos práticos-pesquisadores de histórias de vida em formação, membros da Associação Internacional ASIHVIF (Association Internationale des Histoires de Vie en Formation) a respeito de um conjunto de princípios que traduzem, de um lado, a recusa à instrumentalização de nossos procedimentos e, de outro, o cuidado com a explicitação dos direitos e obrigações contratualmente estabelecidos em nossas ações de pesquisa-formação. A originalidade da metodologia de pesquisa-formação em História de vida situa-se, em primeiro lugar, em nossa constante preocupação em que os autores dos relatos cheguem a uma produção de conhecimento que faça sentido para eles, que se engajem, eles próprios, num projeto de conhecimento que os institua como sujeitos.

Do ponto de vista de uma teoria de formação, a produção dos objetos de saber e de conhecimento a partir das ações com histórias de vida é muito rica, mas também muito individualizada. Os projetos de conhecimento que animam os trabalhos dos/as pesquisadores/as da rede não encontram ainda formulações coletivas que dêem conta, de maneira explícita ou teoricamente coerente, das articulações entre suas conceptualizações singulares. Eu me arriscaria a colocar em debate duas hipóteses de reflexão sobre esse fenômeno. A primeira retoma uma troca recente com Pierre Dominicé no contexto de nossa equipe de pesquisa em Genebra: um dos efeitos sobre os próprios pesquisadores de um trabalho biográfico que valoriza a autonomização do sujeito e a criação de sentidos pelo autor se traduziria por uma busca de singularidade, para não dizer de originalidade intelectual, reforçada pelas regras do jogo da competição universitária. Uma segunda hipótese, que em nada exclui a primeira, consideraria essa dificuldade de sistematização teórica como sendo um resíduo da pregnância de nossas origens disciplinares respectivas, assim como de uma angústia de arriscar-se a uma posição transdisciplinar numa universidade organizada, dominada por territórios disciplinares duramente conquistados e sancionando o “contrabando" entre esses territórios.

É assim que se encontra em todas as obras ou artigos publicados o cuidado de articular a proposta aos referenciais teóricos disciplinares, em detrimento, muito freqüentemente, de um diálogo teórico com as produções dos pesquisadores/as da rede. 0 "Que-sais-Je?" de Gaston Pineau e JeanLouis le Grand (1993) Les histoires de vie e o número da revista Pratiques de Formation Analyses de Paris VIII sobre "Les filiations theóriques des histoires de vie" (1996) são os indicadores mais evidentes.

Ao mesmo tempo, é preciso assinalar duas pequenas iniciativas na direção de uma sistematização. Bem recentemente, em 1999, Gaston Pineau contribuiu para o Traité des sciences et des techniques de la formation, consagrando quatro páginas de seu artigo a uma primeira tentativa de diferenciação das abordagens de histórias de vida a partir da perspectiva de uma análise dos tipos de exploração das experiências de aprendizagem. De minha parte, acabo de arriscar-me a questionar os saberes universitários produzidos pelas histórias de vida, coordenando uma obra (Josso, 2000) na qual reúno textos de um grupo de colegas de cultura e nacionalidade muito diversas, voltados para essa questão e oferecendo uma bibliografia, a mais exaustiva possivel, com publicações do campo das histórias de vida em formação.

Observemos as produções teóricas individuais e seus objetos de conhecimento que testemunham um avanço do projeto "Histórias de vida em formação" ao longo dos dez últimos anos.

A obra de Pierre Dominicé (1990) deve ser novamente mencionada como passagem obrigatória no caminho da delimitação do território da formação ao longo da vida e de seus processos. Logo em seguida, Bernadette Courtois e Gaston Pineau (1991) apresentaram suas contribuições no Colloque sur la 
formation experientielle des adultes, ao mesmo tempo em que publiquei minha tese de doutorado (o sujeito em formação) intitulada Cheminer vers soi (Josso, 1991) e que Gaston Pineau (1997) coordenou sua primeira obra, Reconnaître les acquis. 0 conceito de experiência apresenta-se então como um conceito nuclear dos projetos de conhecimento da formação ao longo da vida.

Guy de Villers (1993) ancora a diferença do seu pensamento em torno da Quête de sens dans l'histoire $d u$ sujet, articulando-a à questão identitária. Gaston Pineau aprofunda sua abordagem da autoformação mediante dois textos-chave: "Histoire de vie comme art formateur de l'existence" (Pineau, 1996) e "Transaction tripolaire et formation permanente" (Pineau,1998). Pierre Dominicé continua sua exploração teórica do território da formação, mostrando "a originalidade epistemológica do saber da formação" (Dominicé,1993) e, em 1995, ele parece reconfigurar seu campo teórico designando-o como "o conhecimento do adulto como objeto de pesquisa biográfica" (Dominicé, 1995). De minha parte, tento mostrar a ampliação de minha concepção de formação em dois textos: "Cheminer vers soi: un processus-projet de connaissance de son existentialité" (no prelo) e "Histoire de vie et sagesse: la formation comme quête d'un art de vivre" (Josso, 1998), publicado em italiano.

Com a segunda geração, a diversificação dos objetos de conhecimento abrem novas perspectivas. Martine Lani-Bayle nos apresenta a questão dos efeitos formadores de uma perspectiva intergeracional entre o adulto e a criança em dois textos: "L'histoire de vie généalogique" (Lani-Bayle,1997) e "L'enfant sur le chemin de son histoire" (no prelo). Pascal Galvani (1997) explora as articulações entre busca de sentido e formação pelo ângulo de uma abordagem biográfica muito original: a construção de seu brasão. Ele enriquece a exploração da autoformação por uma abordagem do simbolismo pessoal que a orienta. Laura Formenti (1998) nos introduz nas articulações conflituais entre abordagem sistêmica e história de vida, na publicação de sua tese de doutorado $L a$ formazione autobiografica: confronti tra modeli e reflessioni tra teoria e prassi. Louise Bourdages (1996) explora o engajamento e a persistência numa tese de doutorado pela construção de um sentido biográfico. Em Normaliennes en Algérie, Malika LemdaniBelkaide (1998) abre em Genebra o campo de uma abordagem biográfica da formação de professores/as, enquanto no mundo lusófono Antônio Nóvoa (1992) e quatro pesquisadoras brasileiras (Bueno, Catani, Sousa e Souza, 1993) desenvolvem abordagens semelhantes. Na mesma direção, Andréa Condamim (1997), no Quebec, publica sua obra Au risque d'être soi. Crise profissionelle: des enseignants se racontent. Dominique Bachelard e Maria Loreto Couceiro introduzem a história de vida no feminino coordenando uma obra coletiva Devenir auteure de sa vie -, a ser publicado pela L'Harmattan. Couceiro faz desse campo o objeto de sua tese de doutorado, centrada sobre a autoformação no feminino a partir de histórias de vida de mulheres ligadas a uma rede feminina de co-formação, depois de ter feito as primeiras observações em um artigo da revista Education Permanente (Couceiro, 1995). Os colegas da rede do Quebec exploram pela primeira vez os efeitos formadores do relato de formação e as dialéticas do "eu" e do "nós" nos relatos (Bourdages; Lapointe; Rheaume, 1998), para mencionar apenas temáticas que os pesquisadores do Quebec trabalharam em simpósios e aos quais se seguiram publicações. Enfim, convém assinalar a tese de doutorado de Jeanne-Marie Rugira, apresentada na Universidade de Quebec em Rimouski, sobre as condições de transformação de uma experiência de sofrimento em experiência formadora que abre com força, pertinência e originalidade o debate sobre as dimensões auto-reparadoras de um procedimento autobiográfico. 
Em nossa equipe de Genebra, o projeto de tese de Jean-Michel Baudoin nos introduz nas articulações entre "histórias de vida, abordagens discursivas e teorias da ação" (a ser publicado). Jacqueline Mombaron trabalha sobre uma tese que busca uma compreensão biográfica de nossas relações com instituições e seu lugar em nossa formação, depois de ter nos apresentado os elementos dessa problemática num artigo a ser publicado, intitulado "Le vécu institutionnel du formateur". Laurence Turkal (1998) tenta compreender a construção biográfica da competência de aprender, enquanto Ronald Muller sensibiliza nossa equipe para a abordagem alemã da lebenswelt ("mundo da vida"), alimentando a dimensão "sensivel" da formação; e Catherine Schmutz-Brun trabalha sobre as articulações entre a escrita do relato e formação (ambos a serem publicados).

Ao longo desse rápido panorama dos projetos de conhecimento que têm como núcleo os procedimentos de histórias de vida em formação, parece-me que a história de vida como projeto de pesquisadores/as e de autores/as poderia ser assim qualificada: $o$ reconhecimento de elaborações e de processos-projetos de formação do nosso ser-estar-no-mundo singular-plural mediante a exploração pluridisciplinar - ou transdisciplinar para alguns - e intersubjetiva de sua complexidade biográfica.

\section{As "histórias de vida" a serviço do desenvolvimento de projetos}

Nesta segunda parte, o termo história de vida vai aparecer entre aspas. Por que? Se é verdade que em certos procedimentos de desenvolvimento de projetos o relato oral ou escrito tenta abranger a totalidade da vida em seus diferentes registros, bem como em sua duração, na maior parte das vezes a história produzida pelo relato é limitada a uma entrada que visa fornecer o material útil ao projeto específico. Nessa última perspectiva, parece-me mais adequado falar de abordagem biográfica ou de abordagem de experiência. Para melhor esclarecer meu propósito, eu gostaria de apresentar quatro exemplos de desenvolvimento de projetos, dentre os vários a que fui solicitada a colaborar nos últimos dez anos.

0 primeiro exemplo refere-se a uma abordagem baseada na experiência a serviço de uma avaliação de competências, tendo em vista um novo referencial profissional desenvolvido junto a cerca de vinte professores/as de uma escola profissional de enfermagem. 0 órgão de controle da profissão, a Cruz VermeIha Suiça, acabara de publicar o novo referencial de competências dos enfermeiros, que deveria servir de base à redefinição dos cursos de formação inicial e de formação contínua oferecidos no conjunto das escolas do território helvécio. Os professores/as deveriam efetuar uma avaliação de suas competências tendo em vista esse referencial, a fim de assegurar seu emprego e assegurar sua capacidade de ensinar essas competências recém definidas. 0 trabalho consistiu na construção de itinerários individuais, desenvolvendo as experiências profissionais ou sociais empregadas com base no novo referencial, bem como as diferentes competências que os caracterizavam. Cada itinerário foi discutido por todos os participantes com o objetivo de colocar em evidência, da forma mais depurada possivel, os pontos fortes e fracos de cada um/a, conduzindo à reflexão sobre as modalidades de uma legitimação ou "validação das aquisições”, pelos especialistas, após esse primeiro trabalho de auto reconhecimento das pessoas.

0 segundo exemplo trata igualmente de uma abordagem baseada na experiência e colocada a serviço da formação inicial em enfermagem, por adultos que retornaram aos estudos. A formação, concebida a partir do novo referencial de competências acima nomeado, explorava novas modalidades pedagógicas, no centro das quais um projeto individualizado de formação permitia aos 
adultos avaliar a defasagem entre as aquisições anteriores, a partir de experiências de vida diversas, e as competências a adquirir ou a desenvolver. Além do mais, foi dada uma atenção particular a seu itinerário escolar, a fim de acompanhar da forma mais adequada possível suas dificuldades nessa retomada dos estudos.

0 terceiro exemplo diz respeito a uma abordagem biográfica temática no quadro de um processo de formação de formadores de enfermeiros, reunindo aproximadamente vinte professores/as e enfermeiros/as clínicos pelo uso da escrita dos relatos de vida no campo da saúde. Nesse caso, a meta era a exploração biográfica de sua formação no cuidado de si e dos outros e, em seguida, trabalhar na transferência das verificações efetuadas durante o processo, tanto na formação inicial, quanto nos serviços de enfermagem.

O quarto exemplo refere-se, novamente, a uma abordagem biográfica temática. Trata-se de um módulo de formação contínua oferecido durante muitos anos pela associação profissional de enfermeiros e enfermeiras do Cantão de Vaud (CH) e pelo serviço de formação contínua vinculado à direção de enfermagem do Hospital Universitário de Genebra. Esse módulo tinha por objetivo ajudar os profissionais a retrabalhar e, desse modo, a ressignificar sua escolha profissional a partir da "História de meus projetos".

Esses relatos bastante heterogêneos em sua natureza e objetivos, ainda que inspirados em minha prática de histórias de vida em formação, não podem ser considerados como "histórias de vida" propriamente ditas. 0 que não desvaloriza em nada o trabalho biográfico efetuado a partir de uma entrada baseada na experiência ou da abordagem temática de um itinerário. Ao apontar essa diferença, pretendo destacar que as "histórias de vida", colocadas a serviço de projetos, são necessariamente adaptadas e restritas ao foco imposto pelo projeto no qual se inserem. Ao passo que as histórias de vida no sentido pleno do termo, para os membros de nossa rede, abarcam a totalidade da vida em todos os seus registros, nas dimensões passadas, presentes e futuras, e, portanto, em sua dinâmica global.

É certo que as tentativas orientadas para projetos profissionais, em todas as suas modalidades, são as que mais se inspiram nos saberes produzidos por nossos processos de história de vida em formação. Na perspectiva do reconhecimento das aquisições, validadas ou não depois, os seminários de Ginette Robin (1988) podem ser considerados exemplares. Laurence Turkal, de Genebra, animou em parceria com ela, durante vários anos, os seminários oferecidos pelo serviço de formação contínua da Universidade de Genebra. Este procedimento é oferecido geralmente a pessoas em busca de uma reorientação, de uma reinserção, mas ela é também experimentada por profissionais que desejam adquirir uma nova ferramenta de trabalho. 0 relato de experiência serve de base a um inventário de capacidades e competências e se traduz em um "portfólio" que ficará como um recurso que a pessoa poderá utilizar tanto em um contexto de emprego quanto em um contexto de formação. No mesmo filão, mas com um procedimento totalmente original pela combinação dos instrumentos utilizados, o coletivo "Espaço de mulheres para a formação e o emprego" utiliza uma abordagem biográfica com mulheres que têm como perspectiva a volta ao trabalho (EFFE, 1998).

Os centros de avaliação de competências que foram constituídos nestes últimos anos devem ser igualmente mencionados nesta perspectiva, pois muitos dentre eles adaptaram os processos autobiográficos de reconhecimento das aquisições. Em Genebra, por exemplo, Pierre Dominicé e eu própria acompanhamos, por mais de uma ano, a reflexão de um pequeno grupo organizado pelo diretor do escritório de orientação profissional na perspectiva biográfica, preparando assim o terreno para a criação de um centro 
genebrino. Os processos de educação de formadores que acompanham os trabalhadores em busca de emprego, inspirados na autobiografia reflexiva de Henri Desroches (1990), tal qual descrita por Jean Avezou (1992), podem ser integrados nesta perspectiva que tem um forte componente profissional. Enfim, Ari Haramein do núcleo de Quebec, aposentado da Universidade de Montreal, oferece no quadro da Associação de Formação de Direito Privado, que ele criou há dois anos em Montreal, uma reflexão biográfica sobre os desafios, as dificuldades e as crises da vida profissional.

Dentre as tentativas de ajuda à inserção social, gostaria de lembrar um organismo comunitário em Quebec - "A caixa postal de Longueuil” -, cujas animadoras, Suzanne Daneau, Françoise Lefebvre e Martine Dupont, membros do núcleo de histórias de vida daquela região, tomam os relatos de experiências autobiográficas de pessoas analfabetas como suporte a um processo de expressão de si e de aprendizagem da leitura e da escrita.

Entre os procedimentos orientados por um projeto de desenvolvimento pessoal, não é raro que o relato de si ou de fragmentos autobiográficos sejam um suporte de trabalho para múltiplas "oficinas de escrita" que proliferaram nos últimos anos. A experiência de Jean Avezou no Oeste francês deve novamente ser aqui assinalada, porque suas oficinas eram explicitamente centradas sobre um trabalho autobiográfico. Eu fui introduzida à dimensão biográfica das oficinas da escritora suiça Mary-Anna Barbey (1997), pela análise crítica que uma de minhas estudantes da Faculté de Psychologie et Sciences de l'Education, Anne-Marie Decrevel, efetuou em seu memorial de licenciatura. Mencionemos igualmente Jeannne-Marie Gingras (1999), que trabalha o relato de seus estudantes da Universidade de Montreal na perspectiva do desenvolvimento de sua criatividade, inspirando-se ao mesmo tempo no Diário de Progoff e nos trabalhos de Vallery.
Um lugar particular deve ser conferido a Jean Vassileff - falecido em 1996 - e co-fundador do Instituto de Pedagogia do projeto em Nantes. Colocando seu trabalho numa perspectiva abertamente sócio-política, as pessoas em formação são convocadas a trabalhar seu relato autobiográfico sob a ótica de colocar seu Desejo em projeto, para desenvolver a capacidade de projeção de si mesmas e de autonomização pessoal.

Para terminar esta segunda parte, gostaria de lembrar um trabalho de fôlego que efetuei com Bernardette Courtois, apresentando as reflexões críticas dos membros de um grupo de pesquisa que ela coordenou na AFPA (Agence Francaise de Formation Professionelle des Adultes) versando sobre os riscos de instrumentalização das "histórias de vida" nas práticas dos/as profissionais de formação, de orientação ou re-orientação, de reinserção social e profissional, e mesmo nas empresas (Josso; Courtois, 1997).

A reflexão sobre as relações entre histórias de vida e construção de projetos está longe de ser um tema esgotado, uma vez que Jean-Pierre Boutinet nos convidou, há pouco tempo, a pensar sobre um projeto de encontro centrado na comparação sistemática entre as metodologias de história de vida e as metodologias do projeto.

\section{Abertura}

Nessa tentativa de balanço sobre história de vida como projeto e as abordagens biográficas ou de experiência a serviço de projetos, eu assinalo dois pontos fortes para o futuro. 0 projeto teórico das histórias de vida em formação testemunhará sua vitalidade, para além das duas primeiras gerações, se os/as pesquisadores/as e práticos/as colocarem como prioridade um trabalho coletivo de articulação teórica dos conhecimentos biográficos produzidos no campo da formação, da auto formação e dos processos que os caracterizam em 
torno de uma perspectiva ético-epistemológica. Além disso, é preciso frisar a necessidade de um trabalho de diferenciação, e portanto de clarificação, de projetos e de práticas de relatos autobiográficos, de abordagens de experiências e de histórias de vida, a fim de nomear mais explicitamente, se necessário, as opções funda- doras do projeto educativo subjacente - centrado sobre o formativo versus o prescritivo que reuniriam o conjunto dessas práticas, e dizer no que elas (práticas e opções) questionam e se situam em ruptura com a concepção e as práticas escolares ainda dominantes na formação inicial e contínua, geral ou profissional.

\section{Referências bibliográficas}

ALHEIT, P. (Org.) The biographical approach in European adult education. Vienne: Verband Wiener Volksbildung, 1995.

AVEZOU, J. Histoire de vie en chômage: un chantier. Quelle formation de formateurs? In: COLLECTIF de Tours. Méthodologie des histoires de vie en formation de formateurs. Paris: Peuple et Culture/Education Permanente, 1992.

BARBEY, M.-A. Femmes, corps et âmes. Genève:Zoé, 1997.

BATESON, G. Vers une écologie de l'esprit. Paris: Seuil, 1980, 2v.

BAUDOUIN, J.-M. La dimension du groupe seconde et primordiale: histoire de vie et recherche-formation. In: BOURGEOIS, E.; SOLAR, C. (Org.) Le groupe en formation des adultes. Université de Bruxelles: De Boeck (no prelo).

Histoires de vie, approches discursives et théories de l'action. In: LERAY, C. (Org.) Histoires de vie et dynamiques langagières. Presses Universitaires de Rennes (no prelo).

BERTALANFFY, L.V. Théorie générale des systèmes. Paris: Dunod, 1972.

BOURDAGES, L. La persistance au doctorat: une histoire de sens. Sainte-Foy, Québec: PUQ, 1996.

.; LAPOINTE, S.; RHEAUME, J. (Coord.) Le " je " et le "nous" en histoire de vie. In: SYMPOSIUM DU RESEAU QUEBECOIS POUR LA PRATIQUE DES HISTOIRES DE VIE, 3, 1998, Paris. Actes du troisième symposium du reseau québécois pour la pratique des histoires de vie. Paris: L'Harmattan, 1998.

BUENO B.;CATANI, D.;SOUSA, C. ;SOUZA, M C. Docência, memória e gênero: estudos alternativos sobre a formação de professores. Psicologia USP, São Paulo, v. 4, nº 1/2, p.299-318, 1993.

CARRE, P.; CASPARD, P. Traité des sciences et des techniques de la formation. Paris: Dunod, 1999.

ESPACE de femmes pour la formation et l'emploi. "Bilan-portfolio" de compétences. Histoire d'une pratique. Lausanne: Editions d'En Bas, 1998.

CONDAMIN, A. Au risque d'être soi. Crise professionnelle: des enseignants se racontent. Québec:Les Editions Septembre, 1997.

COUCEIRO, M. L. Autoformation féminine au carrefour des différents espaces de vie. In: COURTOIS, B.; PREVOST, H. (Org.) Autonomie et formation au cours de la vie. Lyon: Chronique Sociale de France, 1998, p.48-54.

Autoformation et conscientisation du sujet féminin. Education Permanente, Paris, n. 122, 1995, p.56-63.

COURTOIS, B.; G. PINEAU. La formation expérientielle des adultes. Paris: La documentation française, 1991.

DESMARAIS, D.; PILON, J.-M. (Coord.) Pratiques des histoires de vie au carrefour de la formation, de la recherche et de I'intervention. Paris: L'Harmattan, 1996.

DESROCHES, H. Entreprendre d'apprendre: d'une autobiographie raisonnée aux projets d'une recherche-action. Paris: Ouvrières, 1990. 
DOMINICÉ, P. L'histoire de vie comme processus de formation. Paris: L'Harmattan, 1990, 174p.

. L'originalité épistémologique du savoir de la formation. In: JOSSO, M.-C.; BAUDOUIN, J.-M. (Coord.) Penser la formation. Genève: Cahiers de la Section des Sciences de l'Education, 1993.

La connaissance de l'adulte comme objet de recherche biographique. Adultità, Milano, v.1, p.59-63, 1995.

FORMENTI, L. La storia che educa: contesti, metodi, procedure dell'autobiografia educativa. Adultità, Milano, v. 4, p. 91-104, 1996.

La formazione autobiografica: confronti tra modelli e riflessioni tra teoria e prassi. Milano: Guerini e Ass., 1998.

GALVANI, P. Quête de sens et formation: anthropologie du blason et de l'autoformation. Paris: L'Harmattan, 1997.

GINGRAS, J.-M. Le sujet lecteur, auteur et acteur de sa vie. In: CHAPUT, M. (Coord.) Le pouvoir transformateur des histoires de vie. Paris: L'Harmattan, 1999.

GUIBERT-SLEDZIEWSKI, E. Penser le sujet aujourd'hui. Paris: Méridiens KI, 1988.

JoSSO, M.-C. Cheminer vers soi. Paris/Lausanne: L'Age d'Homme, 1991.

. La ricerca della saggezza. Adultità, Milano, v.8, p.103-119, 1998.

La formation au coeur des récits de vie: expériences et savoirs universitaires. Paris: L'Harmattan, 2000.

Cheminer vers soi: un processus-projet de connaissance de son existentialité. In: DOMINICÉ, P. (Org.) A la frontière des disciplines et des histoires de vie. Paris: L'Harmattan (no prelo)

; COURTOIS, B. (Org.) Le projet: nébuleuse ou galaxie? Lausanne: Delachaux et Niestlé, 1997.

LANI-BAYLE, M. L'histoire de vie généalogique. Paris: L'Harmattan, 1997.

L'enfant sur le chemin de son histoire. Toulouse: Erès (no prelo).

LEMDANI-BELKAID, M. Normaliennes en Algérie. Paris: L'Harmattan. 1998.

LEOMANT, C. (Org.) L'histoire de vie au risque de la recherche, de la formation et de la thérapie. Vaucresson: CRIV, 1992.

MISRAHI, R. La problématique du sujet aujourd'hui. Paris: Encre Marine, 1994.

MONBARON, J. Le vécu institutionnel du formateur: un objet de savoir pour soi et pour l'institution. In: DOMINICÉ, P. (Org.) A la frontière des disciplines et des histoires de vie. Paris: L'Harmattan (no prelo)

MORIN, E. La méthode. Paris: Seuil, 1977. 4v.

MULLER, R. Le concept «Lebenswelt » et l'approche biographique en éducation des adultes. In: DOMINICÉ, P. (Org.) A la frontière des disciplines et des histoires de vie. Paris: L'Harmattan (no prelo).

NIEWIADOMSKI, C. Histoires de vie en groupe et approche clinique en alcoologie. D'un préalable "thérapeutique" à un accompagnement "formatif ". Perspective soignante, Paris, n. 4, p. 107-141, av., 1999.

NÓVOA, A. Os professores e as histórias de suas vidas. In: NÓVOA, A. (Org.) Vidas de Professores. Porto: Porto Editora, 1992.

PINEAU, G. (Org.) Accompagnements et histoire de vie. Paris:L'Harmattan, 1988

. (Coord.) Reconnaître les acquis. Paris: L'Harmattan, 1991.

(Coord.) Méthodologie des histoires de vie en formation de formateurs. Paris: Peuple et Culture/Education

Permanente, 1992. 
Histoire de vie comme art formateur de l'existence. Pratiques de formation, Genève, n. 31, p. 65-80, 1996.

Transaction tripolaire et formation permanente. In: FREYN, M.-F. (Coord.) Les transactions aux frontières du social. Lyon: Chronique Sociale, 1998.

; MICHELE, M. Produire sa vie: autoformation et autobiographie. Montréal/Paris: Albert Saint-Martin., 1983.

; JOBERT, G. (Coord.) Histoire de vie. Paris: L'Harmattan, 1989.

; LE GRAND, J.-L. Les histoires de vie. Paris:PUF, 1993. 127p.

ROBIN, G. Guide de reconnaissance des acquis. Boucherville: G. Vermette, 1988.

SCHMUTZ-BRUN, C. Les histoires de vie comme processus de connaissance de son oralité/écriture et processus formateur de dynamiques langagières. Communication au COLLOQUE DE RENNES: CULTURES ET MOUVEMENTS, sept., 1998.

TAYLOR, C. Les sources du moi, la formation de l'identité moderne. Paris: Seuil, 1998.

TURKAL, L. Approche biographique de la dynamique de construction des compétences: apports et manques des formations institutionnalisées. In: DOMINICÉ, P. (Coord.) Les cahiers de la cection des sciences de l'education. Les origines biographiques de la compétence d'apprendre. Genève: Université de Genève, 1998.

VILLERS, G. Quête de sens dans I'histoire du sujet. Questions de formation: produire du savoir. Bruxelles: Université Catholique de Louvain - La Neuve/Faculté Ouverte Pour les Adultes, v. V, n. 10, p. 59-64,1993.

Recebido em 13 abr. 2000

Aprovado em 27 abr. 2000

Marie-Christine Josso é socióloga, antropóloga e doutora em Ciências da Educação pela Universidade de Genebra, onde leciona e pesquisa desde 1971. Participa de diversas sociedades científicas internacionais e desenvolve trabalhos regulares em colaboração com grupos de pesquisadores de Portugal, Canadá, Itália, França e Suíça. Em 1980, funda com Pierre Dominicé o Groupe de Rechercche sur les Adultes et leurs Processus d'Aprentissage (GRAPA) e, em 1990, com ele e vários outros pesquisadores, L'Association Internationale des Histoires de Vie en Formation (ASIHVIF). 